\title{
The Secondary Consequences of Conducting Polls in Political Science Classes: A Quasi-Experimental Test
}

\author{
Lloyd P. Jones, University of North Carolina, Wilmington \\ Stephen S. Meinhold, University of North Carolina, Wilmington
}

W ho benefits most when students conduct public opinion polls in political science classes, the students or the professors? In this article we examine whether students who participate in public opinion polls derive any secondary benefits from their participation beyond the primary goal of learning how to conduct survey research. Specifically, we test whether students' views of the local community are altered by their participation as interviewers in a public opinion poll. Our results suggest that students do not benefit from this type of experience and lead us to question the use of some forms of experiential learning. We end with a call for more systematic research demonstrating the proposed benefits of experiential learning.

Experiential learning is widely used in political science and other disciplines (Kendall et al. 1996). Teachers who use experiential learning in their instruction rarely doubt its efficacy and often recommend its use (see, e.g., Chesney and Feinstein 1993; McBride 1994; Seitz 1994). Students are believed to benefit in three ways from applying their lessons in laboratories, clinics, or offices. First, the application of material presented in the classroom in a real-world setting supposedly increases students' retention and mas-

Loyd P. Jones is associate professor of political science at the University of North Carolina, Wilmington, where he teaches courses in research methods, public policy analysis, and contemporary political issues.

\footnotetext{
Stephen S. Meinhold is assistant professor of political science at the University of North Carolina, Wilmington, where he teaches courses in research methods, constitutional law, judicial politics, and environmental politics.
}

tery of the material. Second, students are assumed to benefit from the social and psychological development that occurs as they face obstacles and engage in interactions in an applied setting. Third, proponents of experiential education argue, students learn the skills required for living and working as employees. That these benefits accrue is taken on face value and the worst case scenario is that they do not.

However, beyond the benefits students in all disciplines seem to realize from experiential learning, there is a fourth set of benefits many advocates of experiential learning in political science claim for students: enhanced citizenship. According to Marando and Melchior, "Internships, community based education, and service learning have all been presented as pedagogical tools for inculcating the mores of active citizenship, breaking down barriers between various groups" (1997, 723). Students who participate in internships and other practical learning situations, in which involvement with a community is central, are believed to develop the skills and perceptions they need to become active, engaged citizens. What seems left unsaid is that these citizenship benefits will be apparent only when the experiential learning fosters a sense of improved citizenship, regardless of other benefits that may be inherent in that learning approach.

This article grew out of our several years of conducting telephone surveys using students as telephone interviewers. Conducting the surveys was part of their training in undergraduate research methods. To conform to the requirements of experiential learning, we incorporated the experience into the course materials closely (Young 1996) and monitored the experiences of our students. As they completed the interviewing, we would discuss their experience with them. This allowed us to monitor the progress of the poll and to gauge students' individual experiences. Many were eager to leave quickly when they finished their shift, but some willingly stayed and talked about their experiences.

We also followed up the surveying experience with a class discussion during which we reinforced the targeted skill acquisition goals. These postpoll analyses were usually lively and involved more students than typical in-class discussions.

As we conducted these postpoll interviews, we noticed that few students reported a negative experience. Indeed, even the few students whose prepoll behavior seemed to signal a resistence to the experience often ended the task with some of the most positive reflections on their work. And, almost invariably, many reported positive experiences even when we had extracted a lot of hard work from them.

This sense that the students were having a positive experience was based, like most of the support for experiential learning, on ad hoc impressions by not altogether unbiased observers. We were biased because we wanted to be good teachers and because the data the students were collecting were useful. The results were disseminated to the local media and used for scholarly and student research. We wanted to believe that the work we were demanding of our students was part of a generally beneficial learning experience. Indeed, we were so convinced our students were benefitting that we began to require telephone polling from students in our substantive classes, 
where poll design and conduct was tangential.

Our experience with them led us to conclude that students benefitted from doing the polling in two ways. First, we convinced ourselves that the students' self-confidence was being enhanced. We reasoned that this new self-confidence resulted from calling random households, facing an uncertain respondent, and then, in most cases, gaining control of a complex and risky situation. We also observed that students gained a sense of satisfaction and reward for completing interviews and finishing a difficult task. We expected these benefits would manifest themselves in students' decreased apprehension in postpoll encounters with strangers.

We also observed what we thought was an improved sense of positive affect toward the community. First-time interviewers often assume that the persons they call are going to hang up on them or not be very cooperative. But, while hangups do occur, the actual experience is that many respondents do talk, often for lengthy periods of time. The students consistently reported that the experience showed them that people do care, know what is going on, and are helpful. Students mentioned many more positive attributes about the people with whom they had spoken than negative ones.

This article reports our attempt to document the secondary benefits we thought we saw arising from the polling experience, which, comfortingly, were consistent with the experiential learning model. Rejecting the old adage that familiarity breeds contempt, we examine whether familiarity and experience breed admiration. We expected that, following their polling, students would come to see community residents as cooperative, knowledgeable about public issues, fair in their judgments, and involved in community affairs.

\section{Research Design}

Using one of our semiannual polls of local residents, we developed a research design to test for the effects of participating in a poll. We fol-

\section{Figure 1 \\ Questions Used to Assess Images of the Community}

\author{
We are interested in your views about the people of Wilmington. For each pair \\ of statements, check the one that best fits your feelings. \\ Most of the time would you say that the people of Wilmington: \\ try to be helpful or are mostly just looking out for \\ themselves \\ try to take advantage of you if they or try to be fair \\ get a chance \\ are warm and friendly or are cold and distant \\ can be trusted or you can't be too careful in dealing \\ with them \\ are knowledgeable about what's going \\ or are mostly uninformed \\ care about what happens in \\ Wilmington
}

lowed a Solomon four-group design (Campbell and Stanley 1963). The treatment was participating in one of our polls. Student interviewers were chosen from courses in research methods, environmental politics, and contemporary political issues. For some students, poll participation was a course requirement. For others, it was a means of earning extra credit. All students who were required to participate worked a four-hour shift. Students earning extra credit worked for two hours.

To examine the hypothesized effects of our polling, we embedded in a questionnaire a series of statements asking each student to choose either a positive or a negative attribute to describe the local community. Figure 1 reproduces the relevant portion of the questionnaire.

The expected positive responses were that the community (i.e., the people of Wilmington, NC) would be seen as helpful, fair, warm and friendly, able to be trusted, knowledgeable, and caring. The community is represented by the random selection of households that were polled. Each interviewer encountered a random cross-section of the community.

The survey instruments were administered to both treatment and control groups (political science students not conducting polls) by psychology graduate students or one of our colleagues. A pretest was administered two days before the sur- vey work commenced. The posttest was administered the day after all surveying had been completed. Both the pre- and posttest instruments contained items about campus life and life in the community in addition to the study variables. On the second instrument, the order and direction of the study variables was altered to reduce the likelihood of identical response sets or contamination due to recall from the earlier instrument. Social security numbers were used for matching the respondents in the analysis.

\section{Analysis}

Did their participation in our poll affect students' attitudes about the Wilmington community? Table 1 displays the means, standard deviations, and number of students for each group. Group 1 is the experimental group, the 53 students who interviewed for at least two hours for whom we collected a pretreatment measurement and a posttreatment measurement. Group 2 is the control group, the 51 students who did not interview but for whom we collected pretreatment and posttreatment observations. These groups are mirrored in experimental groups three and four, whose members were not pretested.

A positive response-a positive perception of the community -is coded 1 , a negative response is coded 0 . Consequently, in Table 1 , a posttest mean that is higher than a 
TABLE 1

Students' Perceptions of Community Characteristics

\begin{tabular}{|c|c|c|c|c|c|c|c|}
\hline \multirow[b]{2}{*}{ Group } & \multirow[b]{2}{*}{ Variable } & \multicolumn{3}{|c|}{ Pretest } & \multicolumn{3}{|c|}{ Posttest } \\
\hline & & Mean & S.D. & $\mathrm{N}$ & Mean & S.D. & $\mathrm{N}$ \\
\hline \multirow[t]{6}{*}{1} & Helpful & .87 & .34 & 47 & .87 & .34 & 53 \\
\hline & Fair & .15 & .36 & 46 & .17 & .38 & 52 \\
\hline & Warm & .96 & .21 & 46 & .89 & .32 & 53 \\
\hline & Trustworthy & .80 & .40 & 46 & .81 & .40 & 53 \\
\hline & Informed & .63 & .49 & 46 & .51 & .50 & 53 \\
\hline & Care & .84 & .37 & 45 & .79 & .41 & 53 \\
\hline \multirow[t]{6}{*}{2} & Helpful & .94 & .24 & 50 & .90 & .30 & 51 \\
\hline & Fair & .08 & .27 & 50 & .06 & .24 & 51 \\
\hline & Warm & .94 & .24 & 50 & .94 & .24 & 51 \\
\hline & Trustworthy & .84 & .37 & 50 & .80 & .40 & 51 \\
\hline & Informed & .90 & .30 & 50 & .82 & .39 & 51 \\
\hline & Care & .90 & .30 & 50 & .96 & .24 & 51 \\
\hline \multirow[t]{6}{*}{3} & Helpful & & & & .68 & .48 & 22 \\
\hline & Fair & & & & .05 & .21 & 22 \\
\hline & Warm & & & & .86 & .35 & 22 \\
\hline & Trustworthy & & & & .59 & .50 & 22 \\
\hline & Informed & & & & .68 & .48 & 22 \\
\hline & Care & & & & .96 & .21 & 22 \\
\hline \multirow[t]{6}{*}{4} & Helpful & & & & .77 & .43 & 30 \\
\hline & Fair & & & & .12 & .34 & 31 \\
\hline & Warm & & & & .90 & .30 & 31 \\
\hline & Trustworthy & & & & .76 & .43 & 30 \\
\hline & Informed & & & & .80 & .41 & 30 \\
\hline & Care & & & & .90 & .31 & 30 \\
\hline
\end{tabular}

Note: Table entries are aggregate values for groups. In addition, pre- and posttest pairs were visually inspected. Lack of individual change made further individual analysis unnecessary.

pretest mean suggests an increase in positive responses. For example, for Group 1, the mean of the item on whether the people of the community are informed is 0.63 in the pretest and 0.51 in the posttest. This indicates that the students in this group, who had all conducted telephone polls, had less esteem for the community's intelligence after the poll than prior to it.

Our most striking finding is that the polling experience did little to effect how students perceived the community. This pattern is evident across all items and in both the control and experimental group. Even where there are differences, the direction of the change on all items and in both groups is toward more negative views of the community. The two exceptions are the trust item for the experimental group and the caring item for the control group.

In sum, comparing the relevant groups, the polling experience produced no detectable changes in students' assessment of the community. Moreover, in Group 1, no more than three students altered their responses between the pretest and the posttest. When we did see an effect, it was consistently contrary to our hypothesis.

\section{Conclusion}

We found no evidence that experiential education makes students better citizens. This finding of no effect has led us to question the anecdotal observations of teachers who hope that experiential learning may have benefits beyond the narrow instructional goals of learning a pop- ular methodology. What we interpreted in student behavior as a positive response to conducting a poll and interacting with the community may simply have been the elation that comes from completing an arduous task. It now seems evident that when students spoke enthusiastically about the people they encountered during their shifts, they were only relating war stories, not some new-found sense of respect and appreciation for the people who make up the community. The polling experience did not alter their perceptions.

Besides the counterintuitive notion that community involvement does not make students stronger community members, there are other factors that might account for our failing to find a positive effect for experiential education. The ef- 
fects of the experience may not be large enough to detect using our instrument. Indeed, looking through the individual responses to the pretreatment instrument, we noted that there were very few negative responses. The students already had a very positive view of the community's characteristics about which we asked. It is possible we did not choose the correct questions to detect the changes that occurred. Students' perceptions of community members' knowledge, fairness, warmth, and caring may not be altered, or alterable, in the course of a telephone poll.

It may also be the case that the treatment level was insufficient to produce measurable effects. Two to fours hours is not sufficient to alter perceptions built up over a student's lifetime. Experiential learning that stretches over longer periods of time-weeks and months-may produce effects that are easier to detect.

It might also be the case that, in future research, we could find more encouraging results for experiential learning by concentrating on the internal effects of the experience rather than external. By ignoring the broader aims of improved sense of citizenship and empathy with the community and reviewing indicators of confidence and sense of accomplishment, we might find the soughtafter effects.

There is a broader, perhaps ethical, implication of these findings. Alan Haskvitz asked in "A Community Service Program that Can Be Evaluated" if programs where students perform service are "anything more than a ploy for the community to arrange free labor?" $(1996,163)$. In light of these findings, we find ourselves forced to ask the same question. Did our goal of conducting unfunded research by exploiting a coercible labor pool lead us to miscalculate the educational benefits to students and to see benefits when they were absent? Could similar miscalculations affect other experientially based approaches where instructors in such programs stand to benefit directly or indirectly in material ways when students pay the costs? We challenge our colleagues to validate the benefits of experiential learning. Furthermore, the validation process should be conducted in a systematic and rigorous fashion by those whose self-interest is not biased toward favorable outcomes.

\section{References}

Campbell, Donald T., and Julian C. Stanley. 1963. Experimental and Quasi-Experimental Designs for Research. Chicago: Rand McNally.

Chesney, James D., and Otto Feinstein. 1993. "Making Political Activity a Requirement in Introductory Political Science Courses." PS: Political Science and Politics 26(September): 535-38

Haskvitz, Alan. 1996. "A Community Service Program that Can Be Evaluated." Phi Delta Kappan 78(October): 163-64.

Kendall, Jane C., John S. Duley, Thomas C.
Little, Jane S. Permand, and Sharon Rubin. 1986. "Why Experiential Learning." In Strengthening Experiential Education within Your Institution, ed. Jane C. Kendall et al. Raleigh, NC: National Society for Internships and Experiential Education.

Marando, Vincent L., and Mary Beth Melchior. 1997. "On Site, Not Out of Mind: The Role of Experiential Learning in the Political Science Doctoral Program." PS: Political Science and Politics 30(December): $723-28$.
McBride, Allan. 1994. "Teaching Research Methods Using Appropriate Technology." PS: Political Science and Politics 27(September): 71-72.

Seitz, John L. 1994. " Now That Was a Good Class': Learning about Politics by Observing Local Government." PS: Political Science and Politics 27(March): 71-72.

Young, Rosalie R. 1996. "Brief Field Experiences: An Instructional Tool for Under graduate Political Science Classes." PS: Political Science and Politics 29(December): $675-76$. 